\title{
Why the macula?
}

\author{
A. C. Bird ${ }^{1} \cdot$ D. Bok $^{2}$
}

Received: 3 October 2017 / Accepted: 9 October 2017 / Published online: 17 November 2017

(c) The Author(s) 2018. This article is published with open access

\begin{abstract}
The regional susceptibility of the retina to diseases has been well known by clinicians for many years. It is surprising that the implications of these observations have not spawned major research efforts to characterise the structural and functional attributes of the outer retina in different regions of a foveate retina. Without such an effort, the understanding of the disease mechanisms in retinal dystrophies will remain limited and may hamper therapeutic efforts. That outer retinal disease is responsible for over $50 \%$ of blind registration in the western world underlines the importance of these considerations.
\end{abstract}

During the last 10 years or so, there has been renewed interest in Type 2 macular telangiectasis. It has been shown that it is a disorder of neurons and glia rather than of blood vessels, as was previously thought, and it is likely that the vascular changes occur as a consequence of neuroglial disease. In addition, the research has also made interesting observations concerning the distribution of change. In early disease, both increased intra-retinal light scatter as shown by blue light reflectance, and loss of luteal pigment as shown by dual wavelength autofluorescence identify a welldefined area of abnormality centred on the fovea [1] (Fig. 1). As the disorder progresses, loss of photoreceptor cells and vascular telangiectasis occur temporal to the fovea and subsequently extend to occupy the area defined by blue light reflectance and dual wavelength autofluorescence but does not extend beyond it. Functional loss corresponds with loss of photoreceptors as shown by optical coherence tomography. These observations pose the question as to why this well-defined retinal region is susceptible to this disease but the remaining retina is destined to be normal, at least clinically. The explanation is likely to be related to both the metabolic attributes of this region of retina that differs from those outside the area, and the functional disturbance generated by the disorder. Concerning the former, little is known. Knowledge of the latter will depend upon

\footnotetext{
A. C. Bird

alan.bird@ucl.ac.uk

1 UCL Institute of Ophthalmology, London, UK

2 Jules Stein Eye Institute, University of California, Los Angeles, CA, USA
}
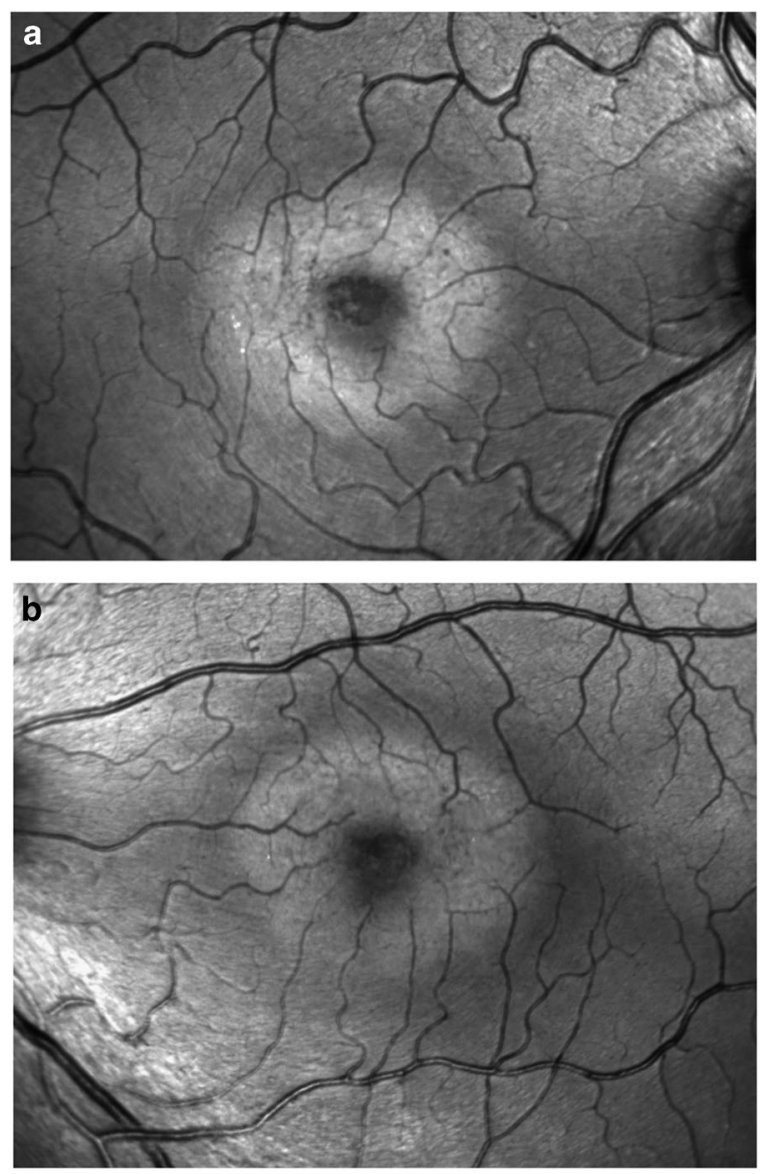

Fig. 1 Blue reflectance images of the right (a) and left (b) eyes in a patient with Type 2 macular telangiectasis showing scatter in a welldefined area centred on the fovea. Photoreceptor loss will occupy this area over time but will not extend beyond it. 

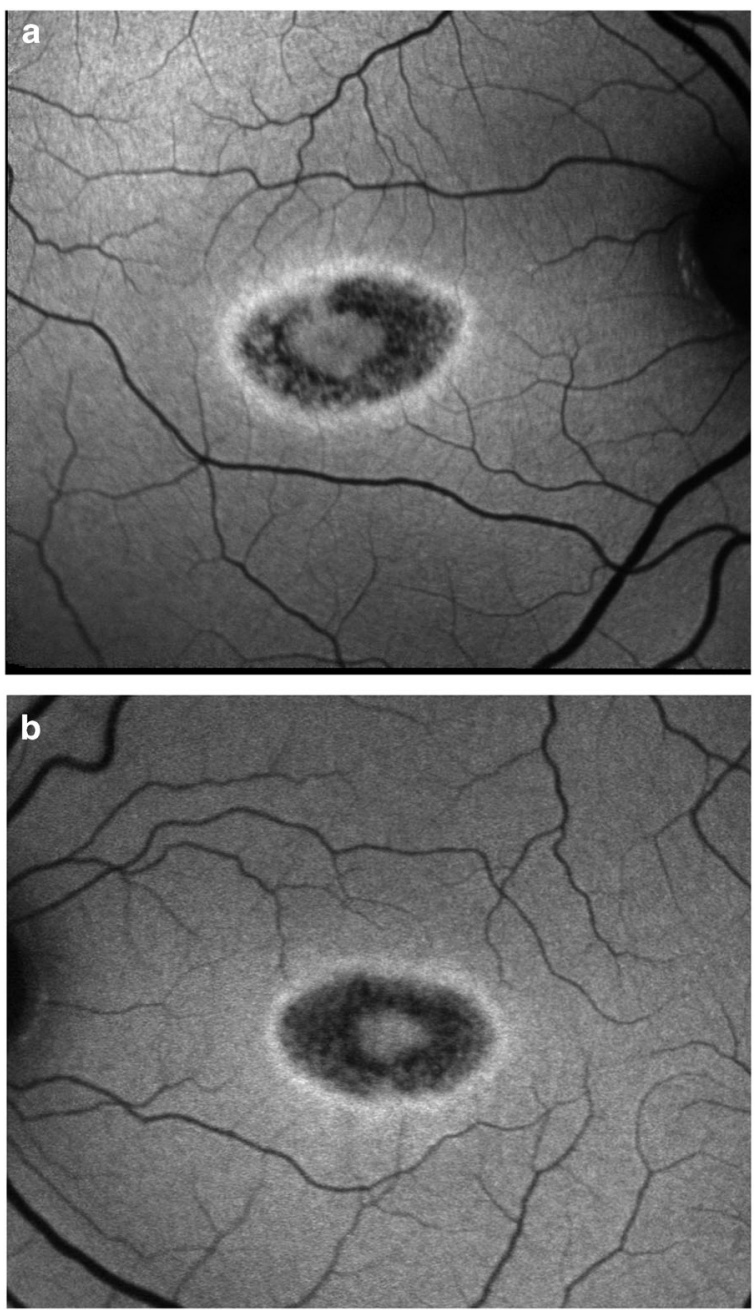

Fig. 2 Autofluorescence image of the right macula (a) and left macula (b) of a patient with Bulls eye dystrophy due to mutations in the $A B C A 4$ gene. A dark ring round the fovea indicates loss of RPE with surrounding heightened autofluorescence implying RPE stress. identification of the genetic variants conferring risk and the metabolic consequences of the variants.

Regional affection of outer retinal diseases in human is not restricted to Type 2 macular telangiectasis and is a characteristic of many disorders. For example, in Bull's eye macular dystrophies outer retinal atrophy encircles the fovea [2], but starts at an eccentricity that differs from one case to another, while sparing the foveola over long periods (Fig. 2). The A2343G mitochondrial mutation causes atrophy in well-defined atrophic patches that are circumferentially orientated and circumferentially distributed around the fovea. These patches enlarge slowly but the fovea may survive for many years [3] (Fig. 3). Similar distribution of atrophy is seen in some cases of geographic atrophy as part of age-related macular disease (Fig. 4) [4]. Central retinal degeneration with foveal sparing is also seen in some cases of Stargardt disease due to mutations in ABCA4 [5] (Fig. 5). The PRPH2 (RDS) 172 mutation causes atrophy centred on the fovea that does not extend beyond the optic disc [6] (Fig. 6). In autosomal dominant Best disease, the deposit and subsequent atrophy is characteristically limited to the fovea [7] (Fig. 7). All these observations illustrate the regional susceptibility of the retina to disease, and highlight the potential relevance of the metabolic attributes of different regions of the retina to the pathogenesis of hereditable macular dystrophies. There are clear physical differences between the macular and peripheral retina. Macular photoreceptor cells have long axons, and the outer segments of foveal cones resemble physically those of rods rather than peripheral cones. In the macula, Müller cells are long and subserve the needs of photoreceptor cells except at the foveolar, where they are short and exist in a 1:1 ratio with cones. Whether or not these physical attributes are associated with differences in functional attributes is unknown and indicates a major gap in knowledge.

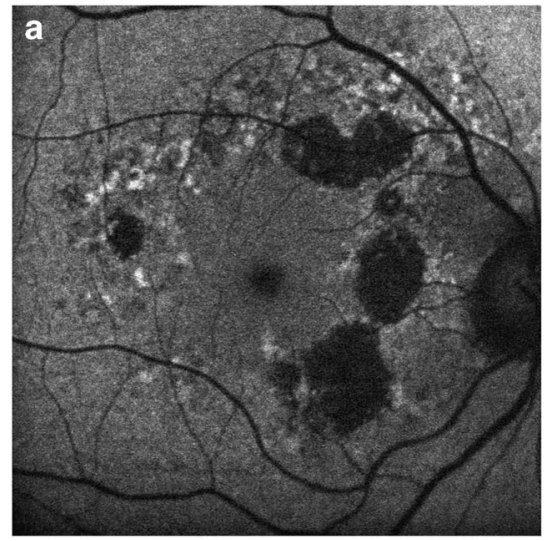

Fig. 3 Autofluorescence images of the right eye of a patient with a A3243G mitochondrial mutation showing loss of RPE as dark patches circumferentially distributed in the macula and diffuse changes of RPE
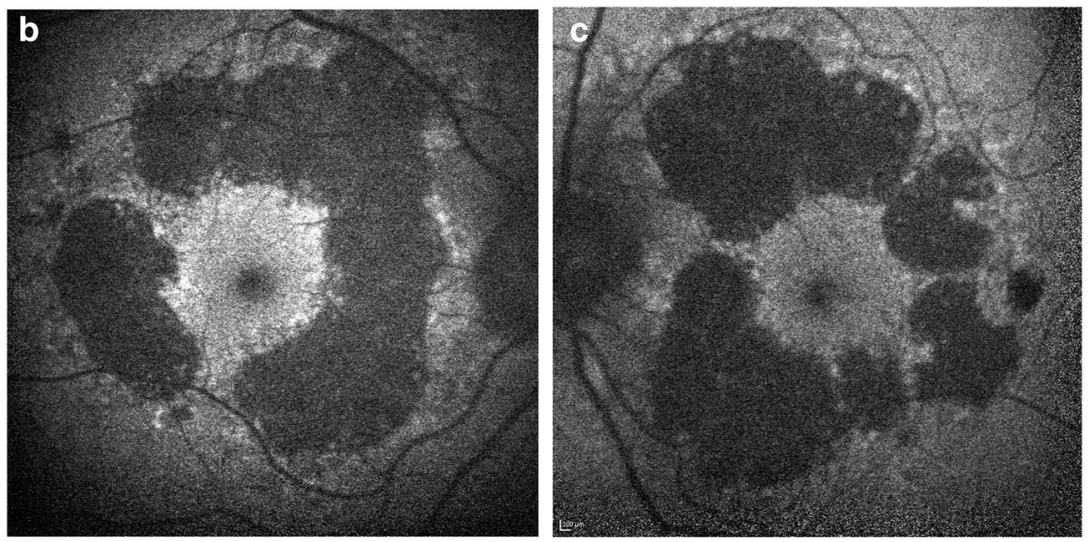

as speckled change over a wider area (a). Five years later, the areas of RPE loss have extended but the fovea has survived (b). A similar appearance is seen in the left eye (c). 


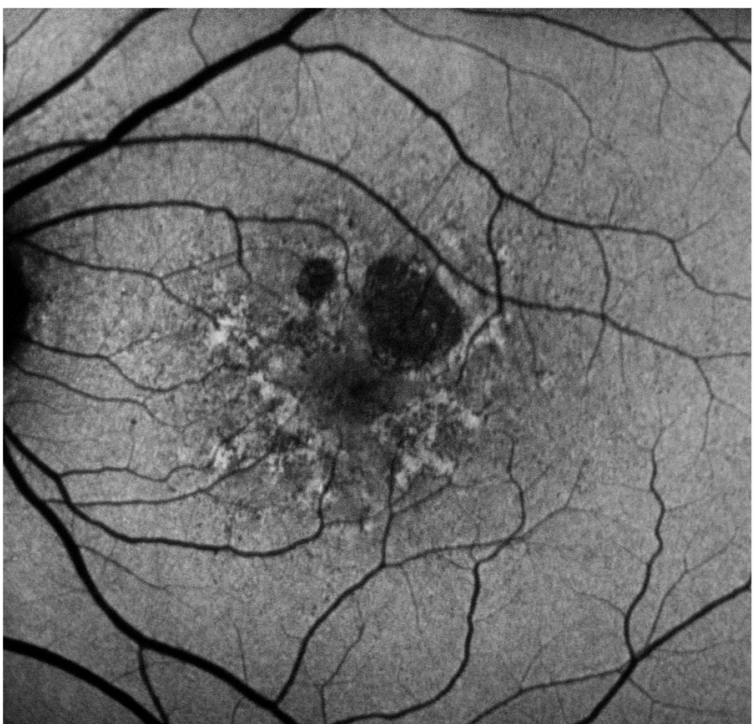

Fig. 4 Autofluorescence of a left eye with geographic atrophy as a manifestation of age-related macular disease showing atrophy of the RPE round the fovea and evidence of RPE stress as irregular autofluorescence with sparing of the fovea.

Recently, major advances have been made in the understanding of outer retinal metabolism particularly with respect to retinal energy generation $[8,9]$. However, the work has been undertaken on rodents that do not possess a macula thus precluding the comparison of functional characteristics of the macula and peripheral retina. Moreover, the clinical observation of foveal sparing implies that major metabolic differences exist between foveolar and nonfoveal macula. It follows that it is important to repeat metabolic investigation of the retina in foveate animals to identify possible explanations for the regional distribution of human diseases. Furthermore, it should not be assumed that the metabolic attributes of the peripheral retina in rodents are similar to those in primates.

These observations imply the need for a major change in research priorities if the understanding of human retinal disease is to be advanced. It is frequently stated that cost precludes the widespread work on primates. However, in large primate colonies death from old age occurs on a regular basis and eyes could be made available at relatively low cost. Large colonies of marmosets exist and their availability may represent a source of eyes that is manageable financially [10]. Marmosets have a well developed macula that is similar to that in human [11-14], and are suitable for anatomical and biological studies $[15,16]$. The practically of Marmosets is manifest by the many who have studied retinal connectivity with higher neural structures and intra-retinal connectivity. This contrasts with the few who have studied outer retinal metabolism.

In addition, the use of human donor eyes could be extended. This is illustrated by the use of post-mortem eyes
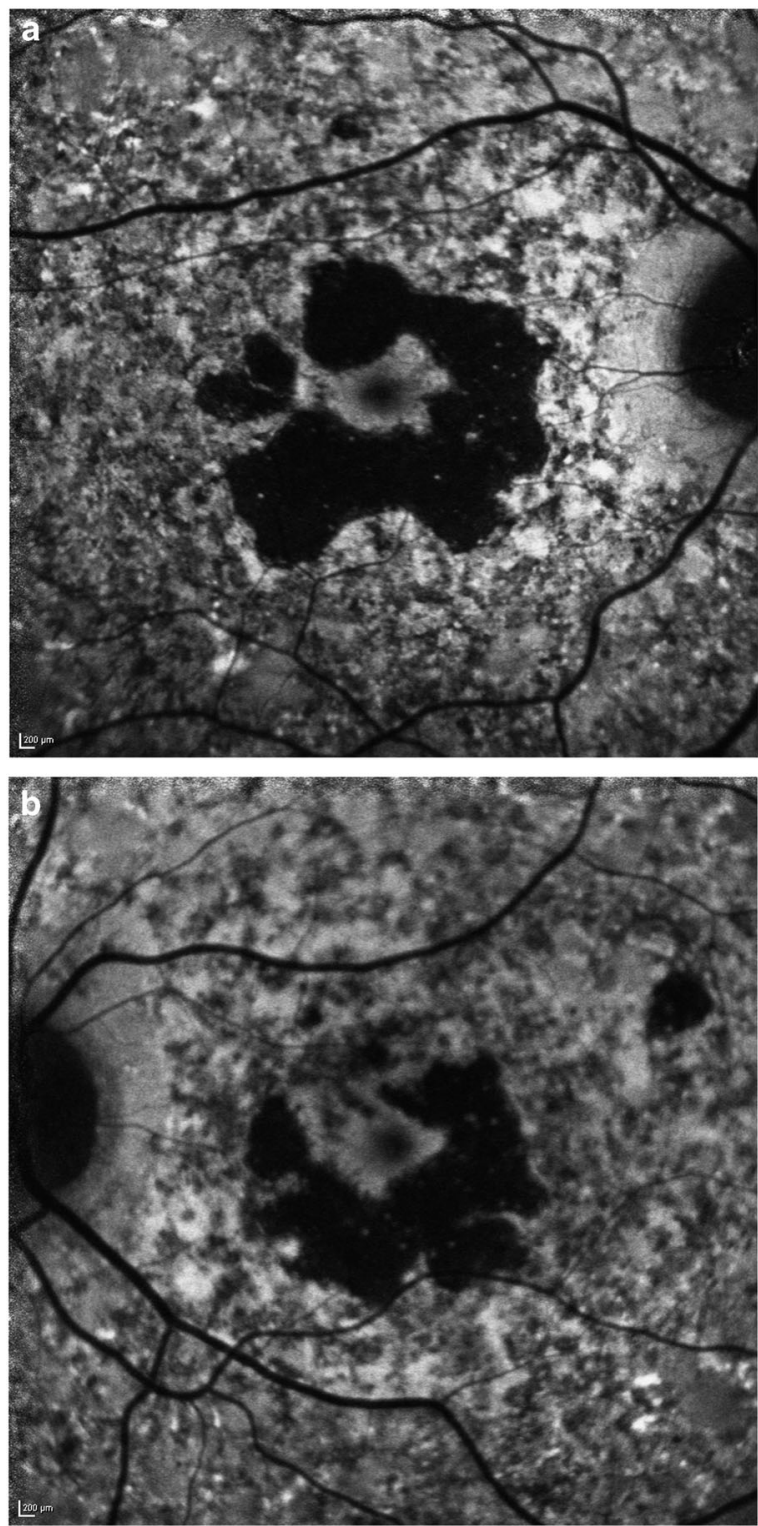

Fig. 5 Autofluorescence of right and left eye images of a patient with Stargardt disease due to mutations in the $A B C A 4$ gene showing RPE loss as dark patches round the fovea with prominent foveal sparing and more widespread RPE abnormality manifest as irregular autofluorescence $(\mathrm{a}, \mathrm{b})$

with and without age-related disease (AMD) donated for research. It has been shown that retinal pigment epithelial mitochondria have accumulated changes that were greater in AMD eyes and in those with the high-risk $C F H$ gene variant when compared with those without AMD and with those with the low-risk CFH variant $[17,18]$. However, the changes were not greater in the macula than in the peripheral retina [19].

It could be argued that, for cell transplantation and gene therapy as therapeutic approaches, these considerations concerning regional retinal metabolic attributes may not be important. However, if pharmacological treatment is to be 


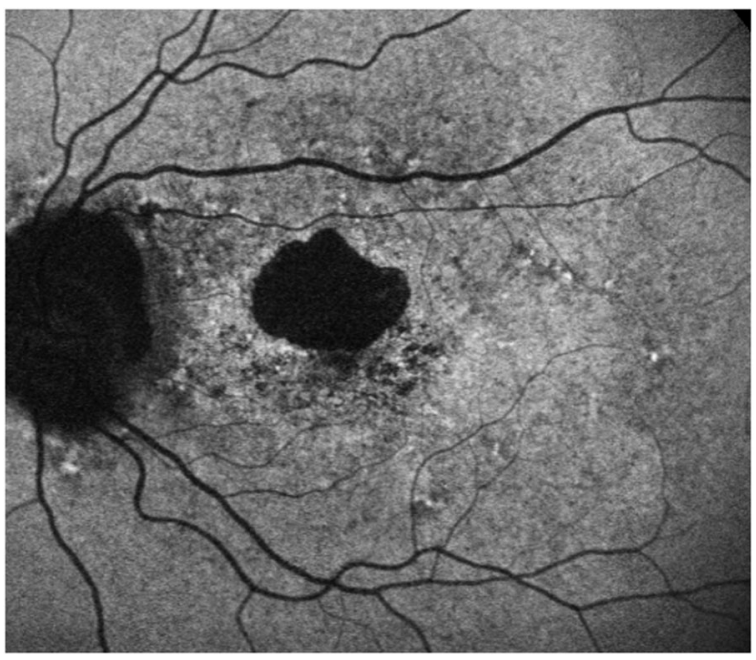

Fig. 6 Autofluorescence image of the left eye of a patient with a 172 mutation in the $P R P H 2$ gene showing absence of RPE as a juxta foveal dark patch with irregular autofluorescence extending to the optic disc indicating RPE stress.

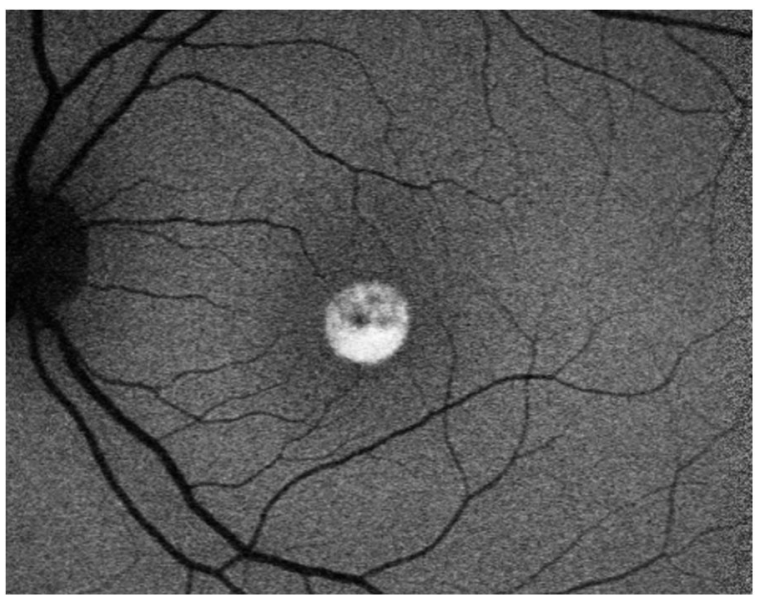

Fig. 7 Autofluorescence image of the left eye of a patient with autosomal dominant Best disease due to a mutation in the VMD2 gene showing accumulation of autofluorescent material at the fovea. Elsewhere the autofluorescence appears normal.

initiated, knowledge of pathogenetic mechanisms of disease may be crucial for success. It may also be the case that knowledge of the metabolic attributes critical to the pathogenesis of retinal dystrophies may be important to verify the suitability of cells for transplantation and of the potential effectiveness of gene therapy. As work on primates progresses, it may allow further investigation that would shed light on the cause of retinal dystrophies other than those affecting the macula. For example, retinitis pigmentosa frequently affects the retina at 12-20 degrees of eccentricity first whatever the genetic mutation involved for which no explanation exists. This is best illustrated by disease due to mutations in the NR2E3 gene [20] (Fig. 8). Whether or not the high density of photoreceptor cells in
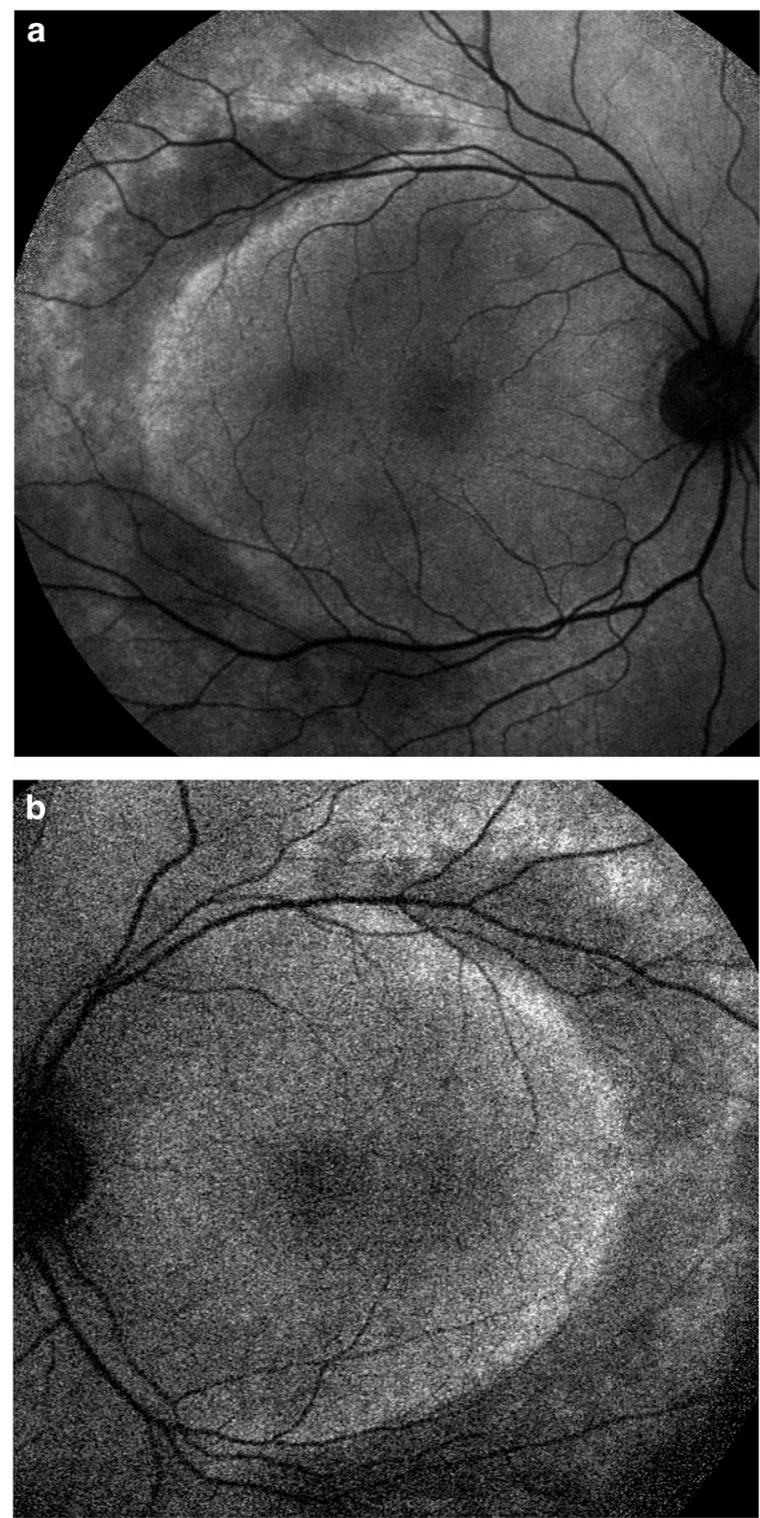

Fig. 8 NR2E3. Autofluorescence images of the right and left eyes in a patient with early retinitis pigmentosa due to a mutation in the NR2E3 gene showing atrophy in an arc at $12-20^{\circ}$ of eccentricity in the temporal fundus $(\mathrm{a}, \mathrm{b})$.

this region is relevant to regional affection in retinitis pigmentosa is not known.

The regional susceptibility of the retina to diseases has been well known by clinicians for many years. It is surprising that the implications of these observations have not spawned major research efforts to characterise the structural and functional attributes of the outer retina in different regions of a foveate retina. Without such an effort, the understanding of the disease mechanisms in retinal dystrophies will remain limited and may hamper therapeutic efforts. That outer retinal disease is responsible for over $50 \%$ of blind registration in the western world underlines the importance of these considerations [21]. 


\section{Compliance with ethical standards}

Conflict of interest The authors declare that they have no competing interests.

Open Access This article is licensed under a Creative Commons Attribution-NonCommercial-NoDerivatives 4.0 International License, which permits any non-commercial use, sharing, distribution and reproduction in any medium or format, as long as you give appropriate credit to the original author(s) and the source, and provide a link to the Creative Commons license. You do not have permission under this license to share adapted material derived from this article or parts of it. The images or other third party material in this article are included in the article's Creative Commons license, unless indicated otherwise in a credit line to the material. If material is not included in the article's Creative Commons license and your intended use is not permitted by statutory regulation or exceeds the permitted use, you will need to obtain permission directly from the copyright holder. To view a copy of this license, visit http://creativecommons.org/licenses/by-nc-nd/4.0/.

\section{References}

1. Sallo FB, Leung I, Zeimer M, Clemons TE, Dubis AM, Fruttiger $\mathrm{M}$ et al. Abnormal retinal reflectivity to short wavelength light in type 2 idiopathic macular telangiectasia. Retina 2017; epub ahead of print 21 June 2017; https://doi.org/10.1097/ IAE.0000000000001728.

2. Duncker T, Tsang SH, Lee W, Zernant J, Allikmets R, Delori FC et al. Quantitative fundus autofluorescence distinguishes ABCA4associated and non-ABCA4-associated bull's-eye maculopathy. Ophthalmology 2015;122:345-55.

3. Bellmann C, Neveu MM, Scholl HPN, Hogg CR, Rath PR, Jenkins $\mathrm{S}$ et al. Localized retinal electrophysiological and fundus autofluorescence imaging abnormalities in maternal inherited diabetes and deafness. Invest Ophthalmol Vis Sci 2004;45:2355-60.

4. Schmitz-Valckenberg S, Fleckenstein M, Helb HM, Charbel Issa P, Scholl HP, Holz FG. In vivo imaging of foveal sparing in geographic atrophy secondary to age-related macular degeneration. Invest Ophthalmol Vis Sci 2009;50:3915-21.

5. Fujinami K, Sergouniotis PI, Davidson AE, Wright G, Chana RK, Tsunoda $\mathrm{K}$ et al. Clinical and molecular analysis of Stargardt disease with preserved foveal structure and function. Am J Ophthalmol 2013;156:487-501.

6. Wells J, Wroblewski J, Keen J, Inglehearn C, Jubb C, Eckstein A et al. Mutations in the human retinal degeneration slow (RDS) gene can cause either retinitis pigmentosa or macular dystrophy. Nat Genet 1993;3:213-17.

7. Sodi A, Passerini I, Murro V, Caputo R, Giacomo Maria Bacci GM, Mirela Bodoj M et al. BEST1 sequence variants in Italian patients with vitelliform macular dystrophy. Mol Vis 2012;18:2736-48.

8. Hurley JB, Lindsay KJ, Du J. Glucose, lactate, and shuttling of metabolites in vertebrate retinas. $J$ Neurosci Res 2015;93:1079-92.

9. Chao JR, Knight K, Engel AL, Jankowski C, Wang Y, Manson MA et al. Human retinal pigment epithelial cells prefer proline as a nutrient and transport metabolic intermediates to the retinal side. J Biol Chem 2017;292:12895-905.

10. Orsia A, Reesa D, Andreini I, Venturel S, Cinelli S, Oberto G. Overview of the marmoset as a model in nonclinical development of pharmaceutical products. Regul Toxicol Pharmacol 2011;59:19-27.

11. Springer AD, Troilo D, Possin D, Hendrickson AE. Foveal cone density shows a rapid postnatal maturation in the marmoset monkey. Vis Neurosci 2011;28:473-84.

12. Franco EC, Finlay BL, Silveira LC, Yamada ES, Crowley JC. Conservation of absolute foveal area in New World monkeys. A constraint on eye size and conformation. Brain Behav Evol 2000;56:276-86.

13. Wilder HD, Grünert U, Lee BB, Martin PR. Topography of ganglion cells and photoreceptors in the retina of a New World monkey: the marmoset Callithrix jacchus. Vis Neurosci 1996;13:335-52.

14. Martin PR, Grünert U. Analysis of the short wavelength-sensitive ('blue') cone mosaic in the primate retina: comparison of New World and Old World monkeys. J Comp Neurol 1999;406:1-14.

15. Böhm MR, Mertsch S, König S, Spieker T, Thanos S. Macula-less rat and macula-bearing monkey retinas exhibit common lifelong proteomic changes. Neurobiol Aging 2013;34:2659-75.

16. Craft CM, Huang J, Possin DE, Hendrickson A. Primate shortwavelength cones share molecular markers with rods. Adv Exp Med Biol 2014;801:49-56.

17. Karunadharma PP, Nordgaard CL, Olsen TW, Ferrington DA. Mitochondrial DNA damage as a potential mechanism for agerelated macular degeneration. Invest Ophthalmol Vis Sci 2010;51:5470-79.

18. Ferrington DA, Kapphahn RJ, Leary MM, Atilano SR, Terluk $\mathrm{MR}$, Karunadharma $\mathrm{P}$ et al. Increased retinal mtDNA damage in the $\mathrm{CFH}$ variant associated with age-related macular degeneration. Exp Eye Res 2016;145:269-77.

19. Terluk MR, Kapphahn RJ, Soukup LM, Gong H, Gallardo C, Montezuma SR et al. Investigating mitochondria as a target for treating age-related macular degeneration. J Neurosci 2015;35:7304-11.

20. Hayashi T, Gekka T, Goto-Omoto S, Takeuchi T, Kubo A, Kitahara K. Novel NR2E3 mutations (R104Q, R334G) associated with a mild form of enhanced S-cone syndrome demonstrate compound heterozygosity. Ophthalmology 2005;112:2115.

21. Quartilho A, Simkiss P, Zekite A, Xing W, Wormald R, Bunce C. Leading causes of certifiable visual loss in England and Wales during the year ending 31 March 2013. Eye 2016;30:602-7. 